\title{
On the study of the transmission networks of blood parasites from SW Spain: diversity of avian haemosporidians in the biting midge Culicoides circumscriptus and wild birds
}

\author{
Martina Ferraguti ${ }^{1 *}$, Josué Martínez-de la Puente ${ }^{1}$, Santiago Ruiz ${ }^{2}$, Ramón Soriguer ${ }^{3}$ and Jordi Figuerola ${ }^{1}$
}

\begin{abstract}
Background: Blood-sucking flying insects play a key role in the transmission of pathogens of vector-borne diseases. However, at least for the case of avian malaria parasites, the vast majority of studies focus on the interaction between parasites and vertebrate hosts, but there is a lack of information regarding the interaction between the parasites and the insect vectors. Here, we identified the presence of malaria and malaria-like parasite lineages harbored by the potential vector Culicoides circumscriptus (Kieffer). Also, we identified some nodes of the transmission network connecting parasite lineages, potential insect vectors and avian hosts by comparing Haemoproteus and Plasmodium lineages isolated from insects with those infecting wild birds in this and previous studies.

Methods: Using a molecular approach, we analysed the presence of blood parasites in a total of 97 biting midges trapped in the Doñana National Park (SW Spain) and surrounding areas. Also, 123 blood samples from 11 bird species were analyzed for the presence of blood parasite infections. Blood parasites Haemoproteus and Plasmodium were identified by amplification of a 478 bp fragment of the mitochondrial cytochrome $b$ gen.

Results: Thirteen biting midges harboured blood parasites including six Haemoproteus and two Plasmodium lineages, supporting the potential role of these insects on parasite transmission. Moreover, ten (8.1\%) birds carried blood parasites. Seven Plasmodium and one Haemoproteus lineages were isolated from birds. Overall, six new Haemoproteus lineages were described in this study. Also, we identified the transmission networks of some blood parasites. Two Haemoproteus lineages, hCIRCUM03 and GAGLA03, were identical to those isolated from Corvus monedula in southern Spain and Garrulus glandarius in Bulgaria, respectively. Furthermore, the new Haemoproteus lineage hCIRCUM05 showed a 99\% similarity with a lineage found infecting captive penguins in Japan.

Conclusions: The comparison of the parasite lineages isolated in this study with those previously found infecting birds allowed us to identify some potential nodes in the transmission network of avian blood parasite lineages. These results highlight the complexity of the transmission networks of blood parasites in the wild that may involve a high diversity of susceptible birds and insect vectors.
\end{abstract}

Keywords: Blood parasites, Haemosporidians, Haemoproteus, Plasmodium, Host parasite interactions, Vector-borne diseases

\footnotetext{
* Correspondence: mferraguti@ebd.csic.es

'Departamento de Ecología de Humedales, Estación Biológica de Doñana (EBD-CSIC), Seville E-41092, Spain

Full list of author information is available at the end of the article
} 


\section{Background}

Vector-borne diseases constitute a major problem affecting human and animal populations [1]. The Haemosporidians (Phylum Apicomplexa) is a group of vector-borne parasites requiring both vertebrate and insect hosts to complete their life cycle. Avian haemosporidians are the largest group of haemosporidians by species number, which include, among others, the malaria parasite Plasmodium and the closely related genera Haemoproteus and Leucocytozoon [2,3]. These parasites require the intervention of blood-sucking insects (Diptera) during their sexual and sporogonic phases along with an intermediate vertebrate host for the merogony phase and the development of gametocytes [3]. Plasmodium and Haemoproteus parasites can infect a broad range of insects showing, however, a certain degree of specificity. Avian Plasmodium species are transmitted by blood-sucking mosquitoes (Culicidae), while Haemoproteus are transmitted by biting midges (Ceratopogonidae) and louse flies (Hippoboscidae) [1,4].

Nowadays, the vast majority of avian malaria studies focus on the interaction between blood parasites and vertebrate hosts [5-8]. However, considering the large number of studies on avian haemosporidians, there is a lack of information targeting the parasites infecting insect vectors (for a recent review [9]). The use of molecular techniques has significantly improved the capacity to identify the networks of avian blood-parasite transmission and has led to a new era on the research of parasiteinsect interactions. However, despite the recent increase in interest toward studies on insects as major vectors in the transmission of avian malaria parasites, the role of vectors on population dynamics of avian malaria parasites in natural ecosystems has been poorly studied. In addition, most studies on potential vectors have been focused on particular insect groups, mainly on mosquitoes [10-14] and black flies [15-17]. In contrast, other groups, as is the case of the biting midges Culicoides Latreille (Diptera: Ceratopogonidae) have been comparatively poorly studied.

Biting midges Culicoides are a diverse and widespread genus with more than 1400 species in the world [18], with at least 81 of them present in Spain [19]. Biting midges transmit pathogens with sanitary importance, including the Bluetongue virus and the emergent Schmallenberg virus $[18,20]$, in addition to the majority of avian Haemoproteus (subgenus Parahaemoproteus) parasites. To fully understand the role of biting midges in the transmission network of blood parasites is essential to reveal the interactions between insects, avian hosts and the blood parasites harboured by the insects. Different studies have revealed the avian hosts of biting midges by identifying the blood meal origin $[21,22]$ or the insect species attracted to birds [23-25]. However, to our knowledge, only three molecular studies have screened the blood parasites harbored by biting midges. In one study, authors identified the blood parasite lineages from individual whole parous females [24] while, in another, Haemoproteus lineages were isolated from pools containing the head-thorax of blood-fed females [17]. Additionally, Santiago-Alarcon et al. [21] isolated blood parasite lineages from the abdomen of blood-fed Culicoides. Therefore, further studies on the role of Culicoides species on the transmission of blood parasites are necessary, as this information is currently missing for the vast majority of Haemoproteus species. This is especially relevant in light of the fact that that these parasites play a key role on the health status and survival probability of avian species [26-28].

Here, using a molecular approach, we identified: i) the Haemoproteus and Plasmodium lineages harboured by the biting midge Culicoides circumscriptus (Kieffer) captured in different areas around the Doñana National Park and ii) the Haemoproteus and Plasmodium lineages infecting wild birds in the studied area in order to identify some nodes of the transmission networks connecting parasite lineages, potential insect vectors and avian hosts. We focus our study on the biting midge C. circumscriptus because this species: i) has an ornithophilic behaviour $[22,23,25]$, ii) has a broad distribution covering most of Europe and North Africa being considered the most abundant ornithophilic species in southern Spain [29] and iii) harbours different blood parasite lineages [24]. Altogether, these studies suggest that $C$. circumscriptus may play a key role on avian blood parasite transmission in the wild.

\section{Methods}

\section{Study area and sample collection}

We studied Culicoides specimens captured from April to June 2008 in different localities from the Doñana National Park and surroundings areas (SW Europe: $38^{\circ} 42^{\prime}-35^{\circ} 59^{\prime} \mathrm{N}$; $\left.7^{\circ} 30^{\prime}-1^{\circ} 38^{\prime} \mathrm{W}\right)$ (Figure 1). Insect trapping was conducted during 24 hours using Center for Disease Control (CDC) incandescent light-traps, powered by a $6 \mathrm{~V}$ battery and baited with $\mathrm{CO}_{2}$. The sampling intervals were two consecutive days per week or two weeks. Traps were hung at 1.60 meters above ground level with the exception of two localities that were placed at two different heights, of 1.60 and 15 meters above ground level. This was done in order to maximize captures of the ornithophilic C. circumscriptus, a species that prefer the canopy level [30]. Insect catches were stored in situ in dry ice and maintained frozen until identification and processing in the laboratory.

As a part of a long-term study on the transmission of West Nile Virus (see [31]), we randomly selected blood samples from 123 birds belonging to 11 species (Table 1) captured from January to December 2009 in the Cañada de los Pájaros (Seville, Spain; 6 $6^{\circ} 4^{\prime} \mathrm{W}, 36^{\circ} 57^{\prime} \mathrm{N}$ ), one of the insect trapping localities. Birds were captured without damage using walk-in-traps and released at the same 


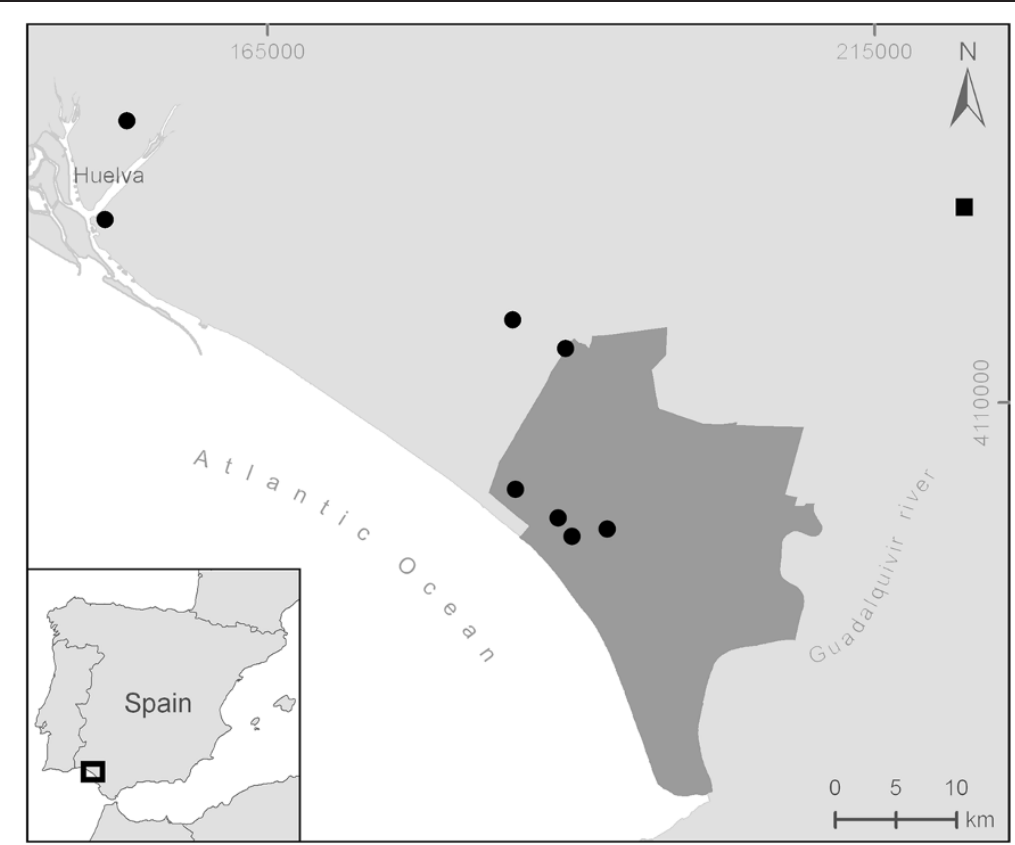

Figure 1 Distribution of the insect (circles and square) and bird (square) sampling sites in the Doñana National Park (in grey) and surrounding areas.

place after sampling. Blood samples were taken with syringes from the tarsal vein and each bird was marked with numbered aluminium rings and released after manipulation. The volume of blood extracted (up to $1 \mathrm{ml}$ ) depended on the size of the species and never exceeded $1 \%$ of avian body mass. In the same day, blood samples were centrifuged and the cell fraction was used for blood parasite identification. Insect collection and bird sampling were performed with all the necessary permits from landowners and regional Department of the Environment (Consejería de Medio Ambiente, Junta de Andalucía).

\section{Insect identification}

All biting midges were transferred to vials containing $70 \%$ ethanol and sorted according to their feeding status under a Zeiss Discovery V8 stereomicroscope. Parous C. circumscriptus females, those that have fed on a host at least once in their life but that did not have visual evidence of blood remains in the abdomen, were isolated as they may be susceptible to transmitting blood parasites. They were identified to species level based on their wing pattern using appropriate taxonomic keys $[32,33]$ and the parous status based on the presence of burgundy-red

Table 1 Number of birds sampled and number of infected individuals (in brackets) for each avian species studied

\begin{tabular}{|c|c|c|c|c|}
\hline Scientific name & Common name & Individuals (infected) & Plasmodium lineage & Haemoproteus lineage \\
\hline Anas acuta & Northern pintail & $8(1)$ & Rinshi-1 & \\
\hline Anas strepera & Gadwall & $7(0)$ & & \\
\hline Aythya ferina & Common pochard & $10(0)$ & & \\
\hline \multirow[t]{2}{*}{ Bubulcus ibis } & Cattle egret & $13(3)$ & GAL-2012+Rinshi-1 $\left(^{*}\right)$ & hBUBIBI01 \\
\hline & & & P15 & \\
\hline Ciconia ciconia & White stork & $15(1)$ & Rinshi-1 & \\
\hline Egretta garzetta & Little egret & $10(1)$ & Delurb5 & \\
\hline Fulica cristata & Crested coot & $24(1)$ & pSPHUj」 & \\
\hline Gallinula chloropus & Common moorhen & $15(1)$ & AFTRU5 & \\
\hline Himantopus himantopus & Black-winged stilt & $6(0)$ & & \\
\hline Marmaronetta angustirostris & Marbled duck & $10(1)$ & Rinshi-1 & \\
\hline Tadorna tadorna & Common shelduck & $5(1)$ & Donana10 & \\
\hline
\end{tabular}

The information on the blood parasite lineages identified for each avian species is given in different columns for Plasmodium and Haemoproteus. $(*)$ One Bubulcus ibis showed co-infection by two different lineages. 
pigmented abdomen that develops during the 1st gonotrophic cycle [34]. Some males and nulliparus females were dissected and mounted for more accurate morphological diagnosis.

\section{DNA extraction and blood parasite identification}

Genomic DNA from 97 randomly selected Culicoides was individually extracted using the DNeasy Blood and Tissue kit (QIAGEN, Hilden). For blood samples, DNA was isolated using the following procedure: a portion of blood clot was pipetted into vials containing $300 \mu \mathrm{l}$ of SET buffer (100 mM NaCl, 50 mM Tris- $\mathrm{HCl}, \mathrm{pH} 8.50 \mathrm{mM}$ EDTA, $\mathrm{pH} 8.0$, SDS $1 \%), 5 \mu \mathrm{l}$ proteinase $\mathrm{K}(20 \mathrm{mg} / \mathrm{ml})$ and $10 \mu \mathrm{l}$ DDT $(1 \mathrm{M})$, and subsequently maintained overnight in a incubating shaker at $55^{\circ} \mathrm{C}$. Once the digestion was completed, an equal volume $(300 \mu \mathrm{l})$ of $5 \mathrm{M} \mathrm{LiCl}$ was added to each tube and each sample was mixed thoroughly by inversion with the addition of $630 \mu \mathrm{l}$ of chloroform-isoamyl alcohol (24:1). Samples were spun and the supernatant (around $500 \mu \mathrm{l}$ ) was carefully transferred to a new tube and the DNA precipitated with absolute ethanol. After recovery by centrifugation, the DNA was dried and washed with $70 \%$ ethanol and the final pellet was recovered and stored in water [35].

Blood parasites Haemoproteus and Plasmodium were identified using the protocol detailed by Hellgren et al. [7] based on the amplification of a 478 bp fragment (excluding PCR primers) of the mitochondrial cytochrome $b$ gen. This procedure is based on a first PCR using primers HaemNFI (5'CATATATTAAGAGAAITATGGAG3') and HaemNR3 (5'ATAGAAAGATAAGAAATACCATTC3'), followed by a nested PCR to amplify Haemoproteus and Plasmodium genera using the primer pair HaemNF (5' ATGGTGCTTTCGATATATGCATG3') and HaemNR2 (5'GCATTATCTGGATGTGATAATGGT3').

Parasite determination was conducted at least twice per sample to avoid false negative samples [36]. Both negative controls for PCR reactions (at least one per plate) and DNA extraction were included in the analysis. Due to strict laboratory protocols and no evidence of contamination in any negative controls, we have assumed that false positives were negligible. Lineages were identified by sequencing the amplicons using the Big Dye 1.1 technology (Applied Biosystems). Labelled DNA fragments of positive PCR products were resolved with an ABI 3130xl automated sequencer (Applied Biosystems) using the same forward and reverse primers used in the nested-PCR amplification. Sequences were edited using the software Sequencher $^{\text {Tm }}$ v 4.9 (Gene Codes Corp., (c) 1991-2009, Ann Arbor, MI 48108) and identified by comparison with the GenBank DNA sequence database (National Center for Biotechnology Information) to assign unknown cytochrome $b$ sequences to previously identified parasite lineages.

\section{Results}

\section{Blood parasite identification from biting midges}

\section{Culicoides}

Thirteen of 97 parous Culicoides females harboured blood parasites. A similar prevalence was found in traps at 1.60 (9 of $62 ; 14.5 \%)$ and at 15 ( 4 of $35 ; 11.4 \%)$ meters above the ground level $\left(\chi^{2}=0.01,1 \mathrm{df}, \mathrm{p}=0.91\right)$. Six Haemoproteus and two Plasmodium different lineages were isolated. One Haemoproteus lineage had a $100 \%$ overlap with lineage GAGLA03 (GenBank accession number: GU085197), isolated in Bulgaria from Garrulus glandarius and five new Haemoproteus lineages were described in this study and sequences deposited in GenBank (number of positive midges and accession numbers are shown in brackets): hCIRCUM01 (from one biting midge, KC994896), hCIRCUM02 (from one biting midge, KC994897), hCIRCUM03 (from three biting midges, KC994898), hCIRCUM04 (from two biting midges, KC994899) and hCIRCUM05 (from one biting midge, KC994900). In these isolates, hCIRCUM03 was identical to a lineage isolated from Corvus monedula from southern Spain in our laboratory (authors unpublished data) and hCIRCUM05 showed a 99\% similarity with the Haemoproteus lineage hAPPAjS (Genbank accession number: AB604312) isolated in Japan from an Aptenodytes patagonicus captive in a zoo. Moreover, the two Plasmodium lineages isolated were identical to previously described sequences corresponding to Rinshi-1 (from Plasmodium relictum) and pSPHUjJ isolated from one and two biting midges, respectively. The rest of the lineages showed a similarity $\leq 98 \%$ with sequences deposited in GenBank database. Sequences obtained from a single biting midge showed double peaks suggesting coamplification of at least two different lineages.

\section{Blood parasites from birds}

Seven Plasmodium and one Haemoproteus lineages were isolated from 10 infected birds (Table 1). One Bubulcus ibis showed mixed infections by two Plasmodium lineages (GAL-2012 and Rinshi-1). Moreover, seven Plasmodium lineages were isolated and completely matched to previously described lineages (sequences published in GenBank database): AFTRU5, GAL-2012 (=GRW6 from Plasmodium elongatum), Delurb5, Donana10, P15, pSPHUjJ and Rinshi-1. In addition, hBUBIBI01, a new Haemoproteus lineage was isolated from a Bubulcus ibis and the sequence deposited in GenBank (accession number: KC994901).

\section{Discussion}

Here, we studied the lineage diversity of blood parasites harbored by the potential vector $C$. circumscriptus and those parasites infecting different bird species from the same area. A total of seven Haemoproteus and seven different Plasmodium lineages were isolated from biting midges and birds. Although studies on blood parasites infecting both birds and potential insect vectors are increasing, 
information on the potential associations between avian malaria parasites and vector species are still scarce and further studies are crucial to fully understand the transmission networks of these parasites in the wild $[15,24,37,38]$. Here, we present valuable information in this respect, but we identify the potential vector and vertebrate hosts of only a few parasite lineages. These results highlight the difficulties in identifying both vertebrate hosts and potential vectors of blood parasite lineages. Based on the previously identified vertebrate hosts of blood parasite lineages isolated from biting midges in this study, we could conclude that $C$. circumscriptus may be involved in the transmission of Haemoproteus parasites from Garrulus glandarius and Corvus monedula, both species belonging to the order Passeriformes. In this respect, it could be possible that we failed to identify more vertebrate hosts of blood parasites because we sampled bird species other than passeriforms. Also, C. circumscriptus could play a significant role in the dynamics of blood parasite transmission infecting exotic species keep in captivity, as may be the case of the penguin Aptenodytes patagonicus in Japan. The last result should be considered important under a conservation perspective as infection by blood parasites Haemoproteus could have dramatic consequences on captive exotic species in zoos $[26,39]$, or in species that do not usually enter into contact with the vector and the pathogen [40].

\section{Haemosporidian parasites in biting midges}

The prevalence of infection by blood parasites found in parous biting midges in this study was similar to those values reported for C. circumscriptus in central Spain [24]. Contrary to the case of another potential vector of avian blood parasites i.e. mosquitoes, it is possible to visually assign parous biting midge Culicoides females according to the pigmentation of their abdomen [34]. This fact may allow researchers to test for the presence of blood parasites only in those females that previously fed on a vertebrate host. Thus, the economic cost of testing unfed females could potentially be reduced, increasing the reliability of prevalence estimates by removing the bias introduced by differences in parous rates among populations, seasons, or species. Also, this fact may increase the parasite prevalence estimation with respect to those studies including unfed insects, as may be the norm on studies on mosquitoes (e.g. [41,42]). However, in some Culicoides species, a percentage of newly emerged females without previous contact with vertebrate hosts, may present abdominal pigmentation being potentially incorrectly identified as parous females [43]. However, as far as we know, this is not the case of $C$. circumscriptus.

In addition to the Haemoproteus lineages, we isolated two Plasmodium lineages from three parous C. circumscriptus biting midges. Avian Plasmodium species are transmitted by mosquitoes most of them belonging to the Culex genus
[3]. Despite this, nowadays, some studies have isolated Plasmodium lineages from biting midges [9,24]. However, these studies were based exclusively on molecular analysis and PCR identification of a parasite lineage does not necessary imply vector competence [44], as positive amplifications could be representative of DNA amplifications of abortive parasite development [45].

\section{Haemosporidian parasites in birds}

Although our results on birds were based on a relatively low sample size, we isolated a considerably high diversity of blood parasite lineages. The most common parasite lineage isolated from birds was Rinshi-1 corresponding to $P$. relictum, which may be potentially transmitted by several mosquito species in the studied area [42]. Also, we have isolated the lineage GAL-2012 (=GRW6) from birds, which have been assigned to the morphospecies Plasmodium elongatum [46]. Both P. relictum and P.elongatum are known to have a broad distribution infecting a wide range of avian species $[3,46]$. Interestingly, a genetic lineage from $P$. elongatum, the parasite species here isolated from Bubulcus ibis was previously found infecting the related Ardea herodias in the USA [see 46]. Only a single Haemoproteus lineage was isolated from birds in this study. This could be due to the lack of samples from Passeriformes and, at least in part, to the fact that birds were sampled in a locality a relatively long way from most of the other insect trapping localities.

Moreover, although the prevalence is low, we isolated blood parasites from the endangered Fulica cristata and Marmaronetta angustirostris. Further studies are necessary in order to identify the potential impact of blood parasite infection on the health and survival of these species.

\section{Conclusions}

The biting midge $C$. circumscriptus may play a key role in some transmission networks of different genetic lineages of the malaria-like parasite Haemoproteus. Overall, results from this study highlight the difficulties in identifying the nodes of these complex transmission networks of blood parasites in the wild that may involve a high diversity of susceptible hosts and insect vectors.

Competing interests

The authors declare that they have no competing interests.

\section{Authors' contributions}

$M F, J M P, S R, R S$, JF were involved in development of the study design. MF and JMP performed the laboratory analysis and data analysis. SR, RS, JF contributed samples/reagents/materials/analysis tools. All authors have read and approved the manuscript.

\section{Acknowledgements}

This study was funded by projects CGL2009-11445 and CGL2012-30759 from the Spanish Ministry of Science and Innovation and co-financed by P07-RNM-02511 and P11-RNM-7038 of the Junta de Andalucía, European Regional Development Funds and by EU grant FP7-261391 EuroWestNile EU grant HEALTH.2010.2.3.3-3 and grant FP7-261504 EDENext. This article is catalogued by the EDENext 
Steering Committee as EDENext143 (http://www.edenext.eu). The contents of this publication are the sole responsibility of the authors and do not necessarily reflect the views of the European Commission. MF and JMP are supported by the FPU Program and by the programme Junta para la Ampliación de Estudios (CSIC) co-financed by Fondo Social Europeo, respectively. We thank Esmeralda Pérez, Juana Moreno Fernandez and Antonio Magallanes Martín de Oliva for their help in field work, insect capture and identification, Isabel Martín for her help with molecular laboratory work and Carlos Moreno and Ernesto García for bird captures. David Aragonés provided advice necessary to generate the map of the study area. Also, we are grateful to Plácido and Maribel for their kindness in allowing us to work in the Cañada de los Pájaros. Two anonymous reviewers provided constructive comments on a previous version of the manuscript.

\section{Author details}

'Departamento de Ecología de Humedales, Estación Biológica de Doñana (EBD-CSIC), Seville E-41092, Spain. ${ }^{2}$ Servicio de Control de Mosquitos, Diputación de Huelva, Huelva E-21003, Spain. ${ }^{3}$ Departamento de Etología y Conservación de la Biodiversidad, Estación Biológica de Doñana (EBD-CSIC), Seville E-41092, Spain.

Received: 20 May 2013 Accepted: 8 July 2013

Published: 15 July 2013

\section{References}

1. Gubler DJ: The global threat of emergent/re-emergent vector-borne diseases. In Vector borne diseases: understanding the environmental, human health, and ecological connections. Edited by Atkinson PW. Washington DC: The National Academies Press; 2010:39-62.

2. Martinsen ES, Perkins SL, Schall JJ: A three-genome phylogeny of malaria parasites (Plasmodium and closely related genera): evolution of life-history traits and host switches. Mol Phylogenet Evol 2008, 47:261-273.

3. Valkiūnas G: Avian Malaria Parasites and Other Haemosporidia. Florida: Boca Raton; 2005

4. Atkinson CT, Van Riper C: Pathogenicity and epizootiology of avian haematozoa: Plasmodium, Leucocytozoon and Haemoproteus. In Bird-parasite Interactions: Ecology, Evolution, and Behavior. Edited by Loye JE, Zuk M. Oxford: Oxford University Press; 1991:19-48.

5. Bensch S, Stjernman M, Hasselquist D, Ostman O, Hansson B, Westerdahl H, Pinheiro RT: Host specificity in avian blood parasites: a study of Plasmodium and Haemoproteus mitochondrial DNA amplified from birds. Proc Biol Sci 2000, 267:1583-1589.

6. van Rooyen J, Lalubin F, Glaizot O, Christe P: Altitudinal variation in haemosporidian parasite distribution in great tit populations. Parasit Vectors 2013, 6:139.

7. Hellgren O, Waldenström J, Bensch S: A new PCR assay for simultaneous studies of Leucocytozoon, Plasmodium, and Haemoproteus from avian blood. J Parasitol 2004, 90:797-802

8. Marzal A, Ricklefs RE, Valkiūnas G, Albayrak T, Arriero E, Bonneaud C, Czirják GA, Ewen J, Hellgren $O$, Hořáková D, lezhova TA, Jensen H, Križanauskienė $A$, Lima MR, de Lope F, Magnussen E, Martin LB, Møller AP, Palinauskas V, Pap PL, Pérez-Tris J, Sehgal RNM, Soler M, Szöllosi E, Westerdahl H, Zetindjiev P, Bensch S: Diversity, loss, and gain of malaria parasites in a globally invasive bird. PLoS One 2011, 6:e21905.

9. Santiago-Alarcon D, Palinauskas V, Schaefer HM: Diptera vectors of avian Haemosporidian parasites: untangling parasite life cycles and their taxonomy. Biol Rev Camb Philos Soc 2012, 4:928-964.

10. Kim KS, Tsuda Y, Sasaki T, Kobayashi M, Hirota Y: Mosquito blood-meal analysis for avian malaria study in wild bird communities: laboratory verification and application to Culex sasai (Diptera: Culicidae) collected in Tokyo, Japan. Parasitol Res 2009, 105:1351-1357.

11. Kim KS, Tsuda Y, Yamada A: Bloodmeal identification and detection of avian malaria parasite from mosquitoes (Diptera: Culicidae) inhabiting coastal areas of Tokyo Bay, Japan. J Med Entomol 2009, 46:1230-1234.

12. Chaves LF, Harrington LC, Keogh CL, Nguyen AM, Kitron UD: Blood feeding patterns of mosquitoes: random or structured? Front Zool 2010, 7:3.

13. Kimura M, Darbro JM, Harrington LC: Avian malaria parasites share congeneric mosquito vectors. J Parasitol 2010, 96:144-151.

14. Takken W, Verhulst NO: Host preferences of blood-feeding mosquitoes. Annu Rev Entomol 2013, 58:433-453.
15. Hellgren O, Bensch S, Malmqvist B: Bird hosts, blood parasites and their vectors-associations uncovered by molecular analyses of blackfly blood meals. Mol Ecol 2008, 17:1605-1613.

16. Sato Y, Tamada A, Mochizuki Y, Nakamura S, Okano E, Yoshida C, Ejiri H, Omori S, Yukawa M, Murata K: Molecular detection of Leucocytozoon lovati from probable vectors, black flies (Simuliidae) collected in the alpine regions of Japan. Parasitol Res 2009, 104:251-255.

17. Synek $P$, Munclinger $P$, Albrecht T, Votýpka J: Avian haemosporidians in haematophagous insects in the Czech Republic. Parasitol Res 2013, 112:839-845.

18. Mellor PS, Boorman J, Baylis M: Culicoides biting midges: their role as arbovirus vectors. Annu Rev Entomol 2000, 45:307-340.

19. Alarcón-Elbal PM, Lucientes J: Actualización del catálogo de Culicoides Latreille, 1809 (Diptera, Ceratopogonidae) de España. Graellsia 2012, 68:353-362.

20. Elbers ARW, Meiswinkel R, van Weezep E, van Oldruitenborgh-Oosterbaan MMS, Kooi EA: Schmallenberg virus in Culicoides spp. biting midges, the Netherlands, 2011. Emer Inf Dis 2013, 19:106-109.

21. Santiago-Alarcon D, Havelka P, Schaefer HM, Segelbacher G: Bloodmeal analysis reveals avian Plasmodium infections and broad host preferences of Culicoides (Diptera: Ceratopogonidae) vectors. PLoS One 2012, 7:e31098.

22. Pettersson E, Bensch S, Ander M, Chirico J, Sigvald R, Ignell R: Molecular identification of bloodmeals and species composition in Culicoides biting midges. Med Vet Entomol 2013, 27:104-112.

23. Martínez-de la Puente J, Merino S, Tomás G, Moreno J, Morales J, Lobato E, Talavera S, Sarto I, Monteys V: Factors affecting Culicoides species composition and abundance in avian nests. Parasitology 2009, 136:1033-1041.

24. Martínez-de la Puente J, Martínez J, Rivero-De Aguilar J, Herrero J, Merino S: On the specificity of avian blood parasites: revealing specific and generalist relationships between haemosporidians and biting midges. Mol Ecol 2011, 20:3275-3287.

25. Votýpka J, Synek P, Svobodova M: Endophagy of biting midges attacking cavity-nesting birds. Med Vet Entomol 2009, 23:277-280.

26. Olias P, Wegelin M, Zenker W, Freter S, Gruber AD, Klopfleisch R: Avian malaria deaths in parrots, Europe. Emerg Infect Dis 2011, 17:950-952.

27. Merino S, Moreno J, Sanz JJ, Arriero E: Are avian blood parasites pathogenic in the wild? A medication experiment in blue tits (Parus caeruleus). Proc Biol Sci 2000, 267:2507-2510.

28. Martínez-de la Puente J, Merino S, Tomás G, Moreno J, Morales J, Lobato E, García-Fraile S, Belda EJ, La Puente JM: The blood parasite Haemoproteus reduces survival in a wild bird: a medication experiment. Biol Lett 2010, 6:663-665.

29. Pérez JM, García-Ballester J, López-Olvera JR, Serrano E: Monitoring bluetongue virus vectors in Andalusia (SW Europe): Culicoides species composition and factors affecting capture rates of the biting midge Culicoides imicola. Parasitol Res 2012, 111:1267-1275.

30. Cerný O, Votýpka J, Svobodová M: Spatial feeding preferences of ornithophilic mosquitoes, blackflies and biting midges. Med Vet Ent 2011, 25:104-108.

31. Figuerola J, Jiménez-Clavero MA, López G, Rubio C, Soriquer R, Gómez-Tejedor C, Tenorio A: Size matters: West Nile Virus neutralizing antibodies in resident and migratory birds in Spain. Vet microbial 2008, 132:39-46.

32. de Heredia MG, la Fuente AG: El género Culicoides en el país Vasco. Guía práctica para su identificación y control. Vitoria-Gasteiz, Spain: Servicio Central de Publicaciones del Gobierno Vasco; 2011:247.

33. Delécolle JC: Nouvelle contribution à l'étude systématique et iconographique des espèces du genre Culicoides (Diptera: Ceratopogonidae) du nord-est de la France. In PhD thesis. France: Université Louis Pasteur de Strasbourg; 1985.

34. Dyce AL: The recognition of nulliparous and parous Culicoides (Diptera: Ceratopogonidae) without dissection. Aus J Ent 1969, 8:11-15.

35. Gemmell NJ, Akiyama S: An efficient method for the extraction of DNA from vertebrate tissues. Trends Genet 1996, 12:338-339.

36. McClintock BT, Nichols JD, Bailey LL, MacKenzie DI, Kendall WL, Franklin AB: Seeking a second opinion: uncertainty in disease ecology. Ecol Lett 2010 13:659-674

37. Gager AB, Del Rosario Loaiza J, Dearborn DC, Bermingham E: Do mosquitoes filter the access of Plasmodium cytochrome $b$ lineages to an avian host? Mol Ecol 2008, 17:2552-2561. 
38. Glaizot O, Fumagalli L, Iritano K, Lalubin F, Van Rooyen J, Christe P: High prevalence and lineage diversity of avian malaria in wild populations of great tits (Parus major) and mosquitoes (Culex pipiens). PLoS One 2012, 7:e34964.

39. Ferrell ST, Snowden K, Marlar AB, Garner M, Lung NP: Fatal hemoprotozoal infections in multiple avian species in a zoological park. J Zoo Wildl Med 2007, 38:209-316.

40. Piersma T: Do global patterns of habitat use and migration strategies co-evolve with relative investments in immunocompetence due to spatial variation in parasite pressure? Oikos 1997, 80:623-631.

41. Njabo KY, Cornel AJ, Bonneaud C, Toffelmier E, Sehgal RNM, Valkiūnas G, Russell AF, Smith TB: Nonspecific patterns of vector, host and avian malaria parasite associations in a central African rainforest. Mol Ecol 2011, 20:1049-1061.

42. Ferraguti M, Martínez-De La Puente J, Muñoz J, Roiz D, Ruiz S, Soriguer RFJ: Avian Plasmodium in Culex and Ochlerotatus mosquitoes from southern Spain: effects of season and host-feeding source on parasite dynamics. PLoS One 2013, 8:e66237.

43. Harrup LE, Purse BV, Golding N, Mellor PS, Carpenter S: Larval development and emergence sites of farm-associated Culicoides in the United Kingdom. Med Vet Entomol. in press.

44. Valkiūnas G: Haemosporidian vector research: marriage of molecular and microscopical approaches is essential. Mol Ecol 2011, 20:3084-3086.

45. Valkiünas $G$, Kazlauskienè R, Bernotienè R, Palinauskas V, lezhova TA: Abortive long-lasting sporogony of two Haemoproteus species (Haemosporida, Haemoproteidae) in the mosquito Ochlerotatus cantans, with perspectives on haemosporidian vector research. Parasitol Res 2013, 112:2159-2169.

46. Valkiūnas $G$, Zehtindjiev $P$, Dimitrov D, Križanauskienè A, lezhova TA, Bensch S: Polymerase chain reaction-based identification of Plasmodium (Huffia) elongatum, with remarks on species identity of haemosporidian lineages deposited in GenBank. Parasitol Res 2008, 102:1185-1193.

doi:10.1186/1756-3305-6-208

Cite this article as: Ferraguti et al:: On the study of the transmission networks of blood parasites from SW Spain: diversity of avian haemosporidians in the biting midge Culicoides circumscriptus and wild birds. Parasites \& Vectors 2013 6:208.

\section{Submit your next manuscript to BioMed Central and take full advantage of:}

- Convenient online submission

- Thorough peer review

- No space constraints or color figure charges

- Immediate publication on acceptance

- Inclusion in PubMed, CAS, Scopus and Google Scholar

- Research which is freely available for redistribution 